\title{
Instructor-Student Rapport in Taiwan ESL Classrooms
}

\begin{abstract}
Positive relationships between instructors and students are critical to effective learning in the classroom. Rooted in the Scholarship of Teaching and Learning (SoTL), and centered at the crossroads of interpersonal communication and instructional communication (Affective Learning Model), this study examines how instructors in a Taiwan ESL school build relationships with Taiwanese students. Instructors were interviewed regarding the behaviors they use to build rapport with their students. Results show that instructors build rapport with their students using several specific techniques: uncommonly attentive behaviors, common grounding behaviors, courteous behaviors, connecting behavior, information sharing behavior, a balancing of connection and authority, adaptation of rapport to student level, and provision of a respite to norms. The findings provide specific examples of how instructors can build rapport in intercultural classrooms.
\end{abstract}

\section{KEYWORDS}

affective learning model, English as Second Language, ESL, rapport, cultural barriers

According to Yam (2009), many recent U.S. college graduates are, due to the current economic climate, looking for unique employment opportunities and one of those opportunities is teaching ESL abroad. Mitch Gordan, director of school relations for Reach to Teach (an ESL recruiting organization), saw the number of applications submitted to his organization increase from approximately 1500 to 3800 applicants during a six-month period in 2009 (Yam, 2009). Many recent college graduates are discovering that teaching abroad can provide more secure employment than seeking a position in the United States (Yam, 2009).

As young adults move abroad to teach, they are faced with the challenging task of effectively communicating with students in a new culture. Students teaching in a different culture have to learn to deal with new traditions, power differentials, norms, and communication styles. Many students who relocate to teach ESL in different countries have completed a college education in the West, and therefore have at least 17 years of exposure to instructor-student relationships in a Western setting that likely influences the way they view instructor-student relationships abroad. 
This study builds on a review of the literature of the Scholarship of Teaching and Learning, instructor-student relationships, and instructor-student rapport, to frame the current investigation of the rapport-building behaviors ESL teachers in Taiwan report using with their students. By studying the rapport-building behaviors of ESL teachers, this study aims to help English teachers in Taiwan overcome cultural barriers and effectively communicate with their students, in order to increase student learning.

\section{LITERATURE REVIEW}

\section{Scholarship of Teaching and Learning}

SoTL research examines a wide array of components of the teaching and learning process, with instructor behaviors garnering a lot of research and attention. McKinney (2007) states that SoTL "often focuses on teachers, teaching strategies, teaching situations, and teaching assignments" (p. 128). Recent SoTL research has focused on various aspects of intercultural communication. For example, SoTL research examined the benefits and challenges of student teaching in intercultural contexts (Lu \& Soares, 2014), communitybased language programs, (Jorge, 2011), and drawing from alumni narratives to improve intercultural communication instruction (Dillon, 2008). The current study adds to the conversation on intercultural communication by exploring the behaviors used by English teachers to build rapport with students in an intercultural classroom.

\section{Instructor-student relationships}

Instructor-student relationships are often a focus of SoTL research and a great deal of research has specifically studied how these relationships affect instructional effectiveness (e.g., Clarke, Flaherty, \& Mottner, 2001; Hill \& Herche, 2001; Schrodt \& Witt, 2006). Much of this research points to the seemingly obvious idea that the relationship between instructors and students has an effect on student learning. Unfortunately, this point is not always as obvious in practice as one might expect. Catt, Miller, and Schallenkamp (2007) suggest that there is frequently a gap between instructor and student perceptions of the qualities of a good instructor; instructors tend to believe that knowledge of a particular subject area is most important, while students rate communication skills as most important. Additionally, Catt et al. (2007) note that shared meaning must be attained for learning to occur; simply presenting an idea does not guarantee that effective communication has occurred.

From an interpersonal perspective, relationship building is vital to effectively communicate instructor knowledge to students. Worley, Titsworth, Worley, and Cornett-Devito (2007) state that classroom relationships are essential to learning, and Dobransky and Fymier (2004) describe instructor-student interactions as interpersonal relationships. Also, Tsui (1996) writes: "establishing a good relationship with students is extremely important in creating a conducive learning atmosphere in the classroom” (p. 164). Clearly, instructor-student relationships are a critical component of an effective classroom.

Extensive research has examined the specific behaviors an instructor can use to create and maintain effective relationships with students. Behaviors positively linked to student learning include: humor (Gorham \& Christophel, 1990), nonverbal immediacy (Frymier \& Houser, 2000), clarity (Chesebro \& McCroskey, 1998), fairness (Faranda \& Clarke, 2004), and caring (Teven \& McCroskey, 1997). These behaviors and subsequent student 
learning outcomes align with the basic assumptions of the Affective Learning Model (ALM) (Rodriguez, Plax, \& Kearney, 1996). This model suggests that positive instructor behaviors (e.g., creating immediacy) are necessary to build relationships between students and instructors, and that these relationships can lead to positive student affect toward the instructor and the class. This positive affect can aid in cognitive learning, which is defined as the recall, knowledge, and development of skills related to course content (Ellis, 2004).

\section{Rapport building}

The process of rapport building has been examined through the lens of the Affective Learning Model. Rapport has been defined and operationalized in different, though complementary, ways. Nadler (2007) defines rapport as positive mutual attention that is marked by affinity and harmony, while Faranda and Clarke (2004) describe rapport as a relationship built on mutual trust and harmony. Gremler and Gwinner (2000) operationalize the term as personal connection and an enjoyable interaction. Recent studies (Frisby, Berger, Burchett, Herovic, \& Strawser, 2014; Frisby \& Martin, 2010; \& Frisby \& Myers, 2008; Webb \& Barrett, in press) have examined how building rapport with students can improve pedagogical effectiveness by increasing student motivation, participation, and learning. Rapport has also been shown to lower student anxiety in the classroom (Coupland, 2003).

Instructor-student rapport is increasingly being viewed as a necessary component of a positive classroom experience. Schrodt and Witt (2006) explain "few can deny the fundamental importance of instructors establishing... rapport with students at the beginning of a new semester" (p. 3). Frisby and Myers (2008), using research by Roach, CornettDevito, and Devito (2005), describe the outcomes of rapport in a classroom setting:

Intuitively, an instructor who maintains positive rapport with students would also achieve a sense of liking from them, increase students' state motivation, and enhance students' satisfaction, in part because student's feelings of liking for instructors often evolves into liking for the course and increased learning (p.28).

Rapport building is clearly a valuable factor in improving student learning, but specific instructor behaviors that build rapport in classroom settings have not been examined in detail. Frisby and Martin (2010) state, "Thus far, rapport seems to be a positive interpersonal construct utilized in the instructional setting. However, it remains unknown exactly which instructor behaviors lead to building rapport with students" (p. 160).

Prior research in non-educational settings claims that rapport is built through a variety of verbal and nonverbal behaviors. In conducting research on rapport in corporate negotiation settings, Nadler (2007) found that rapport is built through nonverbal behaviors such as facing the other person, leaning forward, making eye contact, and mimicry of the other person through posture, facial expressions, tone of voice, and mannerisms. Gremler and Gwinner's (2008) study on rapport-building tactics used in a retail setting identified five ways that retail employees build rapport with customers. These behaviors are: common grounding behavior, connecting behavior, courteous behavior, information sharing behavior, and uncommonly attentive behavior. Common grounding behaviors refer to attempts by the employee to express commonalities between the customer and 
employee. Connecting behaviors are how an employee attempts to develop an interpersonal connection with the customer. Courteous behavior is exemplified through being considerate and kind to customers. Information-sharing behaviors refer to an employee clearly communicating relevant information to the customer. Last, uncommonly attentive behaviors are the behaviors exhibited when an employee goes above-and-beyond what is expected and provides individual attention to a customer.

There are clearly differences between the instructor-student relationship and the employee-customer relationship. Also, the perception of students as customers in higher education is a frequently discussed and highly contested topic (George, 2007). However, this research project is not meant to contribute to that discussion. Instead, this project is designed to focus on how rapport building can effectively be utilized in the classroom. Applying themes from the retail world to an educational setting makes sense in light of the fact that instructor-student relationships and employee-customer relationships both rely on mutual trust (Faranda \& Clarke, 2004), and personal connections and an enjoyable interactions (Gremler \& Gwinner, 2000). Due to the lack of research on specific rapport-building behaviors in instructional settings (Frisby \& Martin, 2010), using the theoretical framework provided by Gremler and Gwinner (2008) to guide the data analysis in the current study is appropriate due to the similar nature of the interpersonal communication in an instructor-student relationship and an employee-customer relationship.

\section{Effective communication in ESL settings}

Recent research on rapport in instructional settings (e.g., Frisby \& Martin, 2010; Webb \& Barrett, in press) has primarily drawn from undergraduate student samples at large public universities in the United States, and therefore may not be generalizable to a broader population. This body of research, although important, has drawn from a relatively homogenous population and, therefore, does not feature a great deal of diversity and/or cultural variance in participants. The current study widens the understanding of rapport in other cultural settings by examining instructor-student rapport in ESL classrooms in Taiwan.

An ESL classroom brings together students and instructors from different cultures. A plethora of cultural differences are present in an ESL classroom and overcoming these differences to effectively build rapport can be a challenge. Americans, for example, are typically regarded as belonging to an individualist culture that emphasizes individual goals, accomplishments, and recognition (Hofstede, 1980). In contrast, Taiwanese are generally regarded as members of a collectivist culture in which the aspirations and wants of individuals are more intertwined with their social groups (Hofstede, 1980). Thus, Americans and Taiwanese may view instructor-student relationships in fundamentally different manners.

Collectivistic cultures typically use high context communication, while individualistic cultures tend to encourage low context communication (Shearman \& Dumlao, 2008). Hall (1976) introduced the idea of "context dependency" which posits that cultural differences affect the way people depend on a particular context when communicating. Hall (1976) explains that high context communication refers to implicit messages where meanings are entrenched in a particular context. In contrast, low context communication refers to explicit messages where the message is overtly stated. In a low context 
culture (like the United States), people express themselves openly and tend to articulate how they are feeling and/or thinking (Shearman \& Dumlao, 2008). In a high context culture (like Taiwan), verbalizing one's thoughts and feelings is not usually viewed in a positive manner, and can even be seen as undesirable. These cultural differences in communication norms are likely to provide obstacles to effective teaching in an ESL classroom.

Research on pedagogical effectiveness has shown that the strategies required to effectively teach ESL are similar to the strategies used in classrooms without language barriers. For example, Chen (2005) posits that ESL instructors should strive to do more than simply teach rote knowledge (in this case, the English language) and instead attempt to also connect with students on a personal and social level. Porto (2010) describes how ESL teachers can connect to students on such a level by "building a culturally pluralistic classroom environment which promotes respect, care, mutual understanding, equality, acceptance of diversity, commitment to anti-racism, etc." (p. 49).

Porto's (2010) description of instructor-student relationships is similar to the tenets of the rapport-building literature, and aligns with recent research on what ESL teachers believe to be important teaching habits. The top three considerations ESL teachers take into account during their program planning and teaching are: building relevant and interesting lessons, analyzing students' current knowledge level and learning goals, and making sure students have appropriate background knowledge and relevant understandings to interact with the curriculum (Hammond, 2008). Implicit in Hammond's (2008) research is an emphasis on rapport building to effectively communicate with ESL students. Brown (1994) supports this proposition and provides extensive guidelines on how instructors can build rapport in classes focusing on language development. Among the rapportbuilding behaviors listed by Brown (1994) are: showing interest in individual students, inviting students to express their thoughts and feelings, and expressing true happiness when students succeed. The current study builds upon Brown's comprehensive research on language classrooms and examines the specific intercultural context of how English instructors in Taiwan build rapport with students.

To gain an understanding of how Western ESL instructors build rapport with Taiwanese students, the following research question was examined:

What instructor behaviors in the classroom do ESL instructors perceive to build rapport with students?

\section{METHOD}

Research was conducted at the Taipei ESL Center (TEC) in Taipei, Taiwan during late May and early June of 2011. TEC is a private school that students attend in the evening to learn English after attending their regular (often public) school during the day. Students can begin taking classes in kindergarten and continue to attend TEC until they graduate from high school. The school has six locations in Taipei and enrolls approximately 600 students, ranging from preschool to high school. The majority of students at TEC are elementary age, but there are also approximately 100 junior high and high school students who attend.

Prior to conducting research at TEC, researchers obtained approval from their university's institutional review board (IRB) to conduct interviews and classroom observa- 
tions. Access to classroom observations and instructors at TEC was facilitated through a personal connection the lead researcher has with one of the directors at TEC. This director functioned as the gatekeeper for TEC, and obtained permission from the head of the TEC for the research to be conducted.

\section{Participants}

Many of the teachers at TEC have relocated to Taiwan to teach English. At the time of the study, there were 26 English teachers at TEC from all around the world, the majority being young adults who recently graduated college. Teachers at TEC are required to have graduated college with at least a bachelor's degree, and preference is given to individuals with prior teaching experience.

Eleven teachers participated in the current study. Seven of the participants were male and four were female. Participant teaching experience ranged from one year to 12 years. Eight of the participants were from the United States, two were from Canada, and one was from England. All of the participants had a bachelor's degree, and two of the participants had master's degrees. Participants ranged in age from 24 to 40 years old, and the average age was 28 .

\section{Procedures}

Three research methods were employed: participant observation, interviews, and field notes. These methods were chosen to provide richness and depth in analysis, as "qualitative inquiry typically focuses in depth on relatively small samples, even single cases $(N=1)$, selected purposefully" (Patton, 2002, p. 230).

Lindlof and Taylor (2011) note, "the value of participant observation derives from the researchers' having been there and done that" (p. 136). To observe instructor-student relationships in an ESL classroom, the first author attended three classes to obtain a first-hand look at how instructors built rapport with students. Time was divided among three different classrooms, and the researcher obtained signed permission from each of the instructors before beginning the observations. The three observations took place in classrooms with nine, ten, and eleven students, respectively. Students observed were in grades eight through eleven. Each observation lasted sixty minutes. Field notes were taken during classroom observations. Van Maanen (1988) describes field notes as, "shorthand reconstructions of events, observations, and conversations that took place in the field" (p. 123). These notes helped to identify themes that were noticed during the research process and to also triangulate interview responses. Classroom observations yielded eight pages of double-spaced typed field notes.

Interviews were conducted at local coffee shops in Taipei. A TEC administrator informed instructors of the study and how they could volunteer to participate. The administrator scheduled interviews with the instructors who volunteered. Prior to beginning each interview, the researcher had each participant read and sign an informed consent statement. Interviews lasted on average 25 minutes and were audio-recorded. A semistructured interview format was used, with interviews focusing on instructor perceptions of building rapport. Specifically, ESL instructors were asked the following question: "What behaviors do you use in the classroom that make you feel that you have built rapport with your students?” 
The interview method was chosen for this study for its ability to "generate rich and descriptive data” (Yu, 2010, p. 25). Upon returning to the United States, interviews were transcribed by undergraduate research assistants, generating 57 single-spaced pages of interview text.

\section{Data analysis}

A thematic analysis was used to analyze the data. Thematic analysis involves a "search for themes that emerge as being important to the description of the phenomenon" (Fereday \& Muir-Cochrane, 2006, p. 3). The themes provided by Gremler and Gwinner (2008) were used to code responses to the interview question about behaviors that build rapport in the classroom. Researchers deductively interpreted units of analysis as words, sentence fragments, complete sentences, or multiple sentence responses, allowing the flexibility to interpret the intentions of the participants.

Throughout the coding process, certain responses were provided multiple times by participants that did align with the five themes found in Gremler and Gwinner's (2008) study. To find new themes in the data, the researchers utilized aspects of Owen's (1984) approach to conducting a thematic analysis. Owen (1984) describes three ways to identify a theme: recurrence, repetition, and forcefulness. Recurrence refers to related data that is observed in multiple segments of a data set. Repetition denotes key words, phrases, and/ or sentences that show up multiple times in participant responses. Forcefulness signifies nonverbal communication such as vocal inflection or dramatic pauses.

\section{RESULTS}

A total of eight themes were identified from the data analysis. Instructor behaviors were categorized by the five themes provided by Gremler and Gwinner's (2008) study: uncommonly attentive behaviors, common grounding behaviors, courteous behaviors, connecting behavior, and information sharing behavior. In addition, three new themes were present in the data: balancing connection and authority, adapting rapport to student level, and providing a respite to norms. Numerous instructor responses included references to multiple types of rapport-building behaviors, indicating the vibrant nature of the construct. Specific behaviors found in each category and examples from instructor responses are discussed below and summarized in Table 1. The example behaviors provided in each theme originated from the research findings, and demonstrate how the framework provided by Gremler and Gwinner (2008) was adapted from a retail to a classroom setting.

\section{Information Sharing Behaviors}

Information sharing behaviors accounted for 26 percent of the mentioned rapport behaviors, making it the most often discussed instructor behavior. Information sharing behaviors include components of instructor credibility and clear instructor-student communication. Instructors who mentioned information sharing behaviors said they provide clear expectations to students and are consistent in following through with their expectations. Examples of information sharing behaviors include

So here, you really need to, the first step is to establish that you know who you are as the teacher and as soon as you know who you are as the teacher, 
Table 1. Rapport Behaviors Described by Instructors

THEME

EXAMPLE

Information sharing behaviors I want to go into the year with certain expectations and guidelines, but also just the first couple days to be like, "These are the expectations of the classroom."

\begin{tabular}{|c|c|}
\hline $\begin{array}{l}\text { Uncommonly attentive } \\
\text { behaviors }\end{array}$ & $\begin{array}{l}\text { So as a teacher my goal is to make them feel, like, good, and that they are } \\
\text { people, and that I care about them. I always say a little love goes a long way; } \\
\text { words of encouragement high fives, things that that really motivate these } \\
\text { students more so than in the West. }\end{array}$ \\
\hline Connecting behaviors & I like to try my best to be fun and joke around with the kids. \\
\hline Courteous behaviors & $\begin{array}{l}\text { Students, they need to know you are fair and respect them and care about } \\
\text { them. }\end{array}$ \\
\hline Common grounding & $\begin{array}{l}\text { So I try to give them stories of when I was their age or things like that which } \\
\text { is more interesting because I'm from a different culture. }\end{array}$ \\
\hline $\begin{array}{l}\text { Balancing connection and } \\
\text { authority }\end{array}$ & $\begin{array}{l}\text { It's a fine line. It's easy to go over, so you have to be constant; you have to } \\
\text { keep in mind how far you can push that. If you go too far then the next thing } \\
\text { you're in trouble and they don't respect you at all. It's a fine line. }\end{array}$ \\
\hline $\begin{array}{l}\text { Adapting rapport to student } \\
\text { level }\end{array}$ & $\begin{array}{l}\text { But, rapport changes based on the level you're teaching as well. High school } \\
\text { class is going to be very different than level two, who is anywhere from 7-8 } \\
\text { years old. It [rapport building] would depend on what age group; it's just } \\
\text { very different. }\end{array}$ \\
\hline Providing a respite to norms & $\begin{array}{l}\text { Students, they need to know you are fair and respect them and care about } \\
\text { them. Asian culture especially the culture tends to be a bit cold and parental- } \\
\text { student relationships often are very business like and typically very cold }\end{array}$ \\
\hline
\end{tabular}

you consistently demonstrate this to your students, because they will call you on it. If you make a rule and then you start jumping through your own loopholes and making exceptions, they'll call you on it and so then they won't believe you.

Keeping clear expectations and from there precedents of this is how things are going to go, like it or leave it, and from there it is just consistency over time... that typically brings about a rapport with the students.

\section{Uncommonly attentive behaviors}

Uncommonly attentive instructor behaviors are present when instructors provide recognition and intense personal interest to students. Specific uncommonly attentive behaviors include: encouraging students, giving students the freedom be creative, providing reward systems, and treating students as individuals. Examples include

I try really hard to encourage students, especially with kids that I can see are struggling more... encouraging them as much as I can in class and setting them up to do well and be successful in class. So, spelling words, I would probably hand them "rest" instead of "poisonous", so they can have that sense of accomplishment and a sense of being correct, I guess.

Uncommonly attentive behaviors accounted for 20 percent of all rapport-building behaviors. 


\section{Connecting behaviors}

Connecting behaviors accounted for 15 percent of the rapport-building behaviors mentioned by instructors. Connecting behaviors include references to humor, providing fun activities, being friendly, and being approachable. As an example,

I try to joke around with them a lot and say silly things, and I think some of that lets them loosen up a little bit, loosen up enough to enjoy me as a teacher.

So, I think quite critically the children will feel quite relaxed around me, because I try to be so friendly and approachable and try to make them laugh.

\section{Courteous behaviors}

Instructors demonstrate courteous behaviors when they are honest, empathic and respectful to students. These behaviors were mentioned 7 percent of the time by instructors. Responses in this category describe instructors as being fair, respectful, and honest. Examples include the following:

It's all about respect.

I'm very honest.

I just show them immediately that I respect them as people as a teacher in the first two weeks my goal is for the students to understand what my boundaries are so that I can respect them.

\section{Common grounding}

Common grounding behaviors were mentioned the least among the themes described by Gremler and Gwinner (2008), with 6 percent of the behaviors mentioned falling in this category. Common grounding behaviors occur when instructors speak on the same level as the student and work to find similarities with students. Instructor comments in this category described sharing stories from their childhood and speaking student's language. Responses describing common grounding behaviors include

There are certain things that over the years of living here you realize what they think is funny, and I can't really narrow it down to what exactly I'm talking about, but it's kind of like a "Chinglish" language where you're mixing up Chinese and English. Sometimes I use that even though I'm not allowed to.

So I try to give them stories of when I was their age or things like that which is more interesting because I'm from a different culture.

\section{Balancing connection and authority}

The difficulty of balancing connection and authority was mentioned in instructor interviews, with 9 percent of the behaviors mentioned describing this tension. This theme refers to an instructor's admission of the difficulty of being perceived as a fun teacher, but the need to be firm. Instructor comments in this category deal with the balance that teachers strive to find in order to connect with students, while remaining in a position of authority. Example responses for this theme include 
I think they like that [using humor]; they say the class is fun. But you have to kind of know where to draw the line so that you are the authority figure. I think in the early years it is more difficult for new teachers because they want to seem like the cool guy, who's a friend to the student, not the authority. They understand what the kid is going through. I think I have it pretty well balanced as to when to stop.

This is an interesting one [rapport building], because this is an area in my teaching that I am looking to improve. I think the last of the three years maybe I'm a little too soft.

\section{Adapting rapport to student level}

Several instructors ( 9 percent of responses) described the different techniques instructors used to build rapport between younger students and older students. Most instructors at TEC teach a wide variety of ages and are aware that rapport needs to be adapted to different audiences. Age differences are quite broad at the school and responses in this category differentiated between older and younger students. Example responses that illustrate this theme include

Now of course there is an in-between, like grade five or six, and I use a mix with them. They know where the boundaries are and I try to get them to be free a little bit, and express themselves. With the in-between kids is a mix. I give the older kids a lot more freedom than I do with the other kids.

\section{Providing a respite to norms}

Eight percent ( 8 percent) of the responses fell into a category that speaks to the ways instructors try to provide an alternative or respite to the student's day-to-day norms. In this theme, teachers wanted to give students a break from what they normally encounter at school and at home. Example responses for this theme include

The interesting thing about Taiwan, which I assume is probably different than in America, but I've never taught in America ... my older kids, I stress for them to express their own opinions and really get them out of their shell because here in Taiwan the way the education system works is these kids are basically stripped of creativity.

They are already so young and being pressured into doing so much. I mean, I don't ever remember writing anything more than a couple of sentences in first grade in the States, and my level one students that are supposed to be equivalent to first graders are writing. I just had them write a fiveparagraph essay for their final exam this week. And I mean, it wasn't super long, it was 160 words but a student that's been studying English for not even two years in our system is already doing that.

\section{DISCUSSION}

These findings support the premise that instructors view building interpersonal relationships with students as important to learning (Dobransky \& Fymier, 2004) in a specific intercultural setting. Although claims cannot be made about all intercultural settings, instructors in this study described rapport building as a widely used tool at one school 
in Taiwan. Open-ended interview questions presented an opportunity for instructors to provide examples of how the interpersonal behavior of rapport building happens in their classrooms.

The Affective Learning Model (Rodriguez, Plax, \& Kearney, 1996) places emphasis on the way affect is the connecting path between instructor immediacy and student learning. The current study supports this model by describing particular behaviors used to facilitate the first step of the affective learning process. Past research has examined the usefulness of rapport building as a construct in the Affective Learning Model (Frisby \& Martin, 2010). However, Frisby and Martin (2010) claimed that it "remains unknown exactly which instructor behaviors lead to building rapport with students" (p. 160). Therefore, the current research strengthens the examination of the usefulness of rapport building by providing concrete examples of the specific behaviors that constitute rapport building. While claims cannot be made regarding the pedagogical effectiveness of each specific category of behavior, it is clear that instructors value rapport-building behaviors and use these behaviors regularly in their ESL classrooms. In addition, the current study provides new categories of behaviors that can be examined in future research on rapport building.

Gremler and Gwinner's (2008) thematic paradigm on rapport building proved to be useful in an intercultural instructional setting. All five of the rapport-building themes were present in instructor's descriptions of rapport-building behaviors. The emergence of all five themes shows that the thematic paradigm is vibrant, and can potentially be employed in a variety of settings.

Of particular interest, among Gremler and Gwinner's (2008) thematic schema, are the most often mentioned rapport-building behaviors (information sharing behaviors; $26 \%$ ) and the least mentioned rapport-building behaviors (common grounding behaviors; $6 \%$ ). In regard to sharing information, the instructors felt a need to explicitly state course information and expectations with their students. This behavior aligns with a low-context style of communication, which is a norm in Western culture (Shearman \& Dumlao, 2008). In addition, instructors, regardless of their years of teaching experience, did not place a great deal of emphasis on finding common ground with students. This behavior supports common individualistic cultural tendencies (Hofstede, 1980) to share information about oneself and to pursue individualistic endeavors, as opposed to focusing on the norms and desires of a larger group. It is not surprising that instructors simultaneously reported utilizing low-context and individualistic communication, as individualistic cultures typically favor low-context communication (Gudykunst \& Ting-Toomey, 1988). In short, it appears that the instructors tend to favor communication patterns that emphasize the norms of their native culture, rather than the communication norms of their students' culture.

The emergence of three new themes: balancing connection and authority; adapting to student level; and providing a respite to norms, adds to the rapport-building literature by providing new ways of understanding how instructors navigate the process of building rapport in an intercultural setting. The three new behaviors were mentioned at a rate similar to two of the five existing rapport-building behaviors employed by Gremler and Gwinner (2008). Each of the new behaviors will be addressed accordingly.

The difficulty of balance points to a tension inherent in the classroom setting. This balance illustrates a relationship dialectic that needs to be examined in other classroom settings. Although rapport building is important to instructors, several spoke about a fine 
line they must walk with their students. While wanting to create a sense of connection and develop an interpersonal relationship with students, instructors realize they need to establish themselves as an authority figure in the classroom. Finding this balance may be a key to effective rapport building.

Adapting to student level demonstrates the need to tread lightly when making claims about how to build rapport with students of different ages. Instructors realized that student relationships are quite different depending on the age of the students, and adjusted their behaviors to accommodate these changes. This finding illustrates a need to conduct research on various student age levels when examining a rapport-building variable. Findings from a study of rapport in an elementary school classroom likely will not always translate to a college setting.

For those teaching abroad, providing a respite to norms offers insights into the process of deciding how to adapt to cultural norms. Some instructors felt that students needed a break from the norms of their typical family and school life. In fact, instructors discussed using these behaviors more often than utilizing common grounding behaviors. Or in other words, some instructors focused more on providing breaks from their students' norms than adapting to them. This finding aligns with the claim that many instructors favor Western norms over the cultural norms of their students. Further research is needed to determine how instructors decide whether or not to provide opportunities for students to go against their normal daily practices, but it is apparent that some instructors felt a need to do so.

Chen (2005) posited that ESL instructors are similar to non-ESL instructors in that they often try to build personal relationships with students. The current research affirmed Chen's claims by showing that building relationships at Taipei ESL Center is similar to Porto's (2010) description of ESL instructor-student relationships that build "a culturally pluralistic classroom environment which promotes respect, care, mutual understanding, equality, acceptance of diversity, commitment to anti-racism, etc.” (p. 49).

\section{Practical implications}

As young adults are increasingly relocating to different countries to teach English (Yam, 2009), it is imperative that administrators of ESL programs include training that emphasizes the importance of building relationships, specifically through rapport building, with students. The current research provides a framework that administrators can use to prepare students to teach English in a different country. Although the effectiveness of these behaviors has not been measured in an ESL setting, they provide a starting point for discussion. Discussions could focus on the specific behaviors that instructors use to build rapport. Trainings could also center on how one manages cultural differences through the rapport-building process. In addition, ESL instructors could dialogue on how rapport building might increase student learning.

\section{Limitations}

There are two main limitations to the current study. First, research was conducted at one specific location, the Taipei ESL Center. Although the research provided a rich understanding of instructors' perspective on rapport building in this particular setting, one must be careful not to make claims about instructor-student rapport in all intercultural or ESL settings. In educational settings outside of Taiwan, Western instructors might ap- 
proach their intercultural communication with students in a different manner. In addition, instructor-student relationships in ESL classrooms may look different depending on the cultural norms of instructors and students.

Second, the research only addressed instructor perceptions of rapport building and did not address student perceptions. Therefore, it is difficult to know if the behaviors listed by the instructors in this context are perceived by their students to build rapport. Although recent studies have made claims about the benefits of rapport building in the classroom (e.g., Frisby \& Martin, 2010; Frisby \& Myers, 2008) and examined student views of rapport building in U.S. college classrooms (e.g. Webb \& Barrett, in press), further research is needed to determine if students perceive these behaviors as building rapport in an intercultural setting. To look at student perceptions, future research could employ student interviews and additional classroom observations to compare and contrast instructor perceptions of rapport building.

\section{CONCLUSION}

Research has established that a large number of English speaking young adults are temporarily relocating to other counties to teach English and that moving to another country to teach English can be a difficult task, especially in the context of communicating with students learning English. The current study has strengthened the Affective Learning Model and rapport building as an affective learning construct by demonstrating specific behaviors instructors perceive to build rapport in an intercultural classroom. New rapport-building themes have emerged through instructor interviews and prior themes have been illustrated in a new setting. This research can be used to improve instructors' ability to build rapport with students in intercultural settings, and serve as a stimulus for additional research on how building rapport can improve student learning.

Nathan G. Webb is Assistant Professor of Communication Studies at Belmont University (USA).

Laura Obrycki Barrett is a Graduate Teaching Assistant in Communication Studies at the University of Kansas (USA).

\section{REFERENCES}

Brown, D.H. (1994). Teaching by Principles: An Interactive Approach to Language Pedagogy. Englewood Cliffs, NJ: Prentice Hall Regents.

Catt, S., Miller, D., \& Schallenkamp, K. (2007). You are the key: Communicate for learning effectiveness. Education, 127, 369-377.

Chesebro, J. L., \& McCroskey, J. C. (1998). The relationship between teacher clarity and immediacy and students' experiences of state receiver apprehension when listening to teachers. Communication Quarterly, 46, 446-455.

Chen, $\mathrm{H}$. (2005). The rationale for critical pedagogy in facilitating cultural identity development. Curriculum and Teaching Dialogue, 7, 11-22.

Clarke, I., Flaherty, T. B., \& Mottner, S. (2001). Student perceptions of educational tools. Journal of Marketing Education, 23, 169-177.

Coupland, J. (2003). Small talk: Social functions. Research on Language and Social Interaction, 36, 1-6. doi:10.1207/S15327973RLSI3601_1 
Dillon, R.K. (2008). How alumni narratives of intercultural competence can inform the scholarship of teaching and learning of intercultural communication. Journal of Scholarship of Teaching and Learning, 8, 36-49.

Dobransky, N., \& Frymier, A. (2004). Developing teacher-student relationships through out of class communication. Communication Quarterly, 52, 211-223.

Ellis, K. (2004). The impact of perceived teacher confirmation on receiver apprehension, motivation, and learning. Communication Education, 53, 1-20.

Faranda, W. T., \& Clarke, I. (2004). Student observation of outstanding teaching: Implications for marketing educators. Journal of Marketing Education, 26, 271-281.

Fereday, J., \& Muir-Cochrane, E. (2006). Demonstrating rigor using thematic analysis: A hybrid approach of inductive and deductive coding and theme development. International Journal of Qualitative Methods, 5, 1-11.

Frisby, B.N., Berger, E., Burchett, M., Herovic, E., \& Strawser, M.G. (2014). Participation apprehensive students: The influence of face support and instructor-student rapport on classroom participation. Communication Education, 63, 105-103.

Frisby, B.N., \& Martin, M. (2010). Instructor-Student and Student-Student Rapport in the Classroom. Communication Education, 59, 146-164.

Frisby, B. N., \& Myers, S. A. (2008). The relationships among perceived instructor rapport, student participation, and student learning outcomes. Texas Speech Communication Journal, 33, 27-34.

Frymier, A. B., \& Houser, M. L. (2000). The teacher-student relationship as an interpersonal relationship. Communication Education, 49, 207-219.

George, D. (2007). Market overreach: The student as customer. The Journal of Socio-Economics, 36, 965-977. doi:10.1016/j.socec.2007.01.025

Gorham, J., \& Christophel, D. M. (1990). The relationship of teachers' use of humor in the classroom to immediacy and student learning. Communication Education, 39, 46-62.

Gremler, D. D., \& Gwinner, K. P. (2000). Customer-employee rapport in service relationships. Journal of Service Research, 3, 82-104. doi:10.1177/109467050031006

Gremler, D. D., \& Gwinner, K. P. (2008), Rapport-building behaviors used by retail employees. Journal of Retailing, 84, 308-324. doi:10.1016/j.jretai.2008.07.001

Gudykunst, W. B., \& Ting-Toomey, S. (1988). Culture and interpersonal communication. Newbury Park, CA: Sage.

Hall, E. T. (1976). Beyond culture. Garden City, NJ: Anchor.

Hammond, J. (2008). Intellectual challenge and ESL students: Implications of quality teaching initiatives. Australian Journal of Language \& Literacy, 31, 128-154.

Hill, M. E., \& Herche, J. (2001). Teaching and effectiveness: Another look. Marketing Education Review, 11,19-24.

Hofstede, G. (1980). Culture's consequences: International differences in work-related values. Beverly Hills, CA: Sage.

Jorge, E. (2011). Assessing the value of a community-based approach to language and cultural learning: A longitudinal study. Journal of Scholarship of Teaching and Learning, 11, 33-52. 
Lindlof, T.R. \& Taylor, B. C. (2011). Qualitative communication research methods. Thousand Oaks, CA: Sage.

Lu, H.S. \& Soares, L. (2014). US elementary preservice teachers' experiences while teaching students in Taiwan. Journal of Scholarship of Teaching and Learning, 14, 59-72.

McKinney, K. (2007). Enhancing learning through the scholarship of teaching and learning. Bolton, MA: Anker.

Nadler, J. (2007). Build rapport-and a better deal. Negotiation, 3, 9-11.

Owen, W. F. (1984). Interpretive themes in relational communication. Quarterly Journal of Speech, 70, 274-287. doi:10.1080/00335638409383697

Patton, M. Q. (2002). Qualitative research and evaluation methods. Thousand Oaks, CA: Sage.

Porto, M. (2010). Culturally responsive L2 education: An awareness-raising proposal. ELT Journal: English Language Teachers Journal, 64, 45-53. doi:10.1093/elt/ccp021

Roach, K. D., Cornett-DeVito, M. M., \& DeVito, R. (2005). A cross-cultural comparison of instructor communication in American and French classrooms. Communication Quarterly, 53, 87-107. doi:10.1080/01463370500056127

Rodriguez, J. I., Plax, T. G., \& Kearney, P. (1996). Clarifying the relationship between teacher nonverbal immediacy and student cognitive learning: Affective learning as the central causal mediator. Communication Education, 45, 293-305.

Schrodt, P., \& Witt, P. (2006). Students' attributions of instructor credibility as a function of students' expectations of instructional technology use and nonverbal immediacy. Communication Education, 55, 1-20.

Shearman, S. M., \& Dumlao, R. (2008). A cross-cultural comparison of family communication patterns and conflict between young adults and parents. Journal of Family Communication, 8, 186-211. doi:10.1080/15267430802182456

Teven, J. J., \& McCroskey, J. C. (1997). The relationship of perceived teacher caring with student learning and teacher evaluation. Communication Education, 46, 1-9.

Tsui, A. (1996) Reticence and anxiety in second language learning. In Bailey, D. Nunan and M. Swan (Eds.), Voices From the Language Classroom: Qualitative Research in Second Language Education (pp. 145-167). Cambridge: Cambridge University Press.

Van Maanen, J. (1988). Tales of the field: On writing ethnography. Chicago: University of Chicago Press.

Webb, N.G. \& Barrett, L.O. (in press). Student views of instructor-student rapport in the college classroom. Journal of Scholarship of Teaching and Learning.

Worley, D., Titsworth, S., Worley, D., W. \& Cornett-DeVito, M. (2007). Instructional communication competence: Lessons learned from award-winning teachers. Communication Studies, 58, 207-222. doi:10.1080/10510970701341170

Yam, E. (2009). Young Americans going abroad to teach. Retrieved from http://articles.cnn .com/2009-03-20/travel/teaching.abroad_1_japan-exchange-and-teaching-applicants -job-market?s=PM:TRAVEL.

$\mathrm{Yu}, \mathrm{H}$. (2010). Bring workplace assessment into business communication classrooms: A proposal to better prepare students for professional workplaces. Business Communication Quarterly, 73, 21-39. 